\title{
Knowledge and Perceptions of Extension Workers on Sustainable Agricultural Practices
}

\author{
${ }^{1}$ Neda Tiraieyari, ${ }^{1}$ Azimi Hamzah, ${ }^{1}$ Bahaman Abu Samah and ${ }^{2}$ Jegak Uli \\ ${ }^{1}$ Institute for Social Science Studies, University Putra Malaysia, Malaysia \\ ${ }^{2}$ Faculty of Defence Studies and Management, National Defense University of Malaysia, Malaysia
}

Received 2012-10-04, Revised 2013-02-06; Accepted 2013-03-19

\begin{abstract}
Due to the expansion of crop productions there has been an increase in the fertilizers' use by farmers in Malaysia. Recently Sustainable Agricultural Practices (SAP) is gaining attention within agricultural sector. The Department of Agriculture facilitates regular delivery of SAP knowledge to farmers through extension workers. However extension workers' perceptions and knowledge on SAP is not known well in Malaysia. A survey of extension workers was conducted in peninsular Malaysia to identify their perceptions and knowledge about SAP and determine the extent to which extension workers communicate SAP to the farmers. A descriptive research design was used to collect data from 400 extension workers. Results suggest extension workers' perceptions and knowledge of SAP are favorable. Extension workers indicated that they communicate SAP information to the farmers. Further investigation from farmers' perspectives is required to discover to what extent extension plays significant role in promoting adoption of the program.
\end{abstract}

Keywords: Extension Worker, Knowledge, Perception, Sustainable Agriculture

\section{INTRODUCTION}

Sustainable agriculture is effective management of agricultural resources to fulfill human needs, preserve the environment and enhance biological resources (Chikwendu and Arokoyo, 1997). Most definitions include three components: economic soundness, environmental protection and social acceptance (Fairweather and Campbell, 2003; Bell et al., 2001; Williams, 2000). Malaysia is an agricultural society that is developing quickly into an industrial country (Salleh et al., 2007). The country has 4.06 million hectares of farmland of which $80 \%$ are planted with industrial crops (Murad et al., 2008). Ninety percent of Malaysian farmers in the food sector are smallholders, operating uneconomically sized farms with high production costs, low inputs, low yield and poor product quality (Tiraieyari and Uli, 2011; Ahmad, 2001). The Malaysian government's policy toward agriculture emphasizes increasing production to achieve food self-sufficiency. The challenge of producing enough food for security and self-sufficiency resulted in an insensitive farming system and, consequently, environmental damage (Barrow et al., 2009). In recent years, Sustainable Agriculture Practices (SAP) were implemented to transform agriculture into a sustainable sector. Government agencies took positive measures to reduce chemical fertilizers and use resources sustainably. To reduce fertilizers in crop production, the Department of Agriculture (DOA) promotes practices such as Integrated Farming Systems (IFS), good Agricultural Practices (GAP) and Organic Farming (OF) (Tiraieyari and Uli, 2011). Although recent Malaysian policies are compatible with sustainable agricultural standards, contemporary practices in the country differ slightly from sustainability (Murad et al., 2008). Transformation of unsustainable agricultural practices into sustainable ones requires farmers to adopt the program. Since sustainable agricultural systems include extensive information systems, agricultural extension workers play a key role in helping farmers adopt programs. According to Chizari et al. (1999) the first step in

Corresponding Author: Neda Tiraieyari, Institute for Social Science Studies, University Putra Malaysia, Malaysia 
adoption is providing SAP information to those extension workers. In this study we surveyed extension workers who work directly with farmers to answer the following questions: (1) what are extension workers' perceptions toward sustainable agriculture concepts, (2) what is the level of extension workers' knowledge on sustainable agriculture? and (3) to what extent do extension workers communicate SAP knowledge to the farmers?

\subsection{Theoretical Framework}

Historically, extension workers played a vital role in helping the agricultural system, but for them to assist with SAP; they must understand sustainable agriculture concepts (Agunga, 1995; Udoto and Flowers, 2001). The effectiveness of sustainable agricultural depends to a large extent on the ability of extension workers to transfer sustainable practices to the farmers (Tiraieyari and Uli, 2011). Extension workers play a central role in assisting farmers make decisions regarding adoption of SAP (Udoto and Flowers, 2001). Despite the fact that sustainable agriculture is vital, extension workers' knowledge and understanding of the concept is inadequate (Minarovic and Mueller, 2000). Al-Subaiee et al. (2005) contends that the first step in sustainable agriculture planning is to train extension workers to develop understanding and qualifications. Some researchers report that extension workers experience problems understanding the sustainability concept (Chizari et al., 2006; Allahyari, 2008). Agunga (1995) suggests extension workers in Ohio; USA did not possess good understanding of sustainable agriculture and were uninterested in promoting the program. Coffnner and Kolodinsky (1997) reveals that extension workers in New England, USA also had a negative attitude toward sustainable agriculture, implying extension workers' uncertainty toward sustainable agriculture may be due to lack of knowledge. Attitudes of Iranian agricultural extension professionals, including extension workers, were found unfavorable Allahyari (2008). Results of a study conducted by Minarovic and Mueller (2000) suggest extension workers' attitudes reflect they realize the importance of sustainable agricultural and are knowledgeable about the concept. However, when asked about actions taken to apply a systems-thinking philosophy as a way to define their attitudes toward sustainable agriculture, there was no evidence of strong effort.

Promoting sustainable development is a challenge agricultural extension faces. Adoption of sustainable practices by farmers is essential to change unsustainable agriculture into a sustainable system. According to Singh and Osawaru (1990) barriers to adoption of sustainable agriculture include lack of information for farmers and disseminating information to them. Barrow et al. (2009) reports adoption of sustainable practices in Cameron Highlands, Malaysia is less encouraged by extension workers. They conclude government organizations could identify and extend the right support to encourage SAP faster. Extension services play a key role in providing information on sustainable agriculture. Hence, they must be trained in sustainable agriculture to develop understanding, perceptions and abilities to teach practices to farmers (Bonne et al., 2007). Minarovic and Mueller (2000) states extension services play a critical role in the evolution of sustainable agriculture education. Thus, it is vital to understand the level of extension workers' knowledge about the concept to move a program forward. Agunga (1995) reported extension workers should be convinced of the value of sustainability. Otherwise, how can they educate farmers? Based on studies conducted by (Alonge and Martin, 1995; Straquadine, 1985; Udoto and Flowers, 2001) extensions workers' perceptions of SAP were favorable and supporting SAP.

\subsection{Purpose and Objectives}

The objectives of this study were to (1) describe socio-demographics of respondents, (2) determine extension workers' perceptions on SAP, (3) determine extension workers' knowledge on SAP and (4) determine to what extent extension workers communicate the SAP to the farmers.

\section{MATERIALS AND METHODS}

This study was conducted in peninsular Malaysia and data were gathered from a survey of agricultural extension workers who work at the DOA, working directly with farmers. Four hundred workers were selected randomly from west Malaysia and a descriptive research method was used to collect data from respondents. Collecting perceptions of SAP, the first part of the instrument was adopted from previous studies conducted by (Connors et al., 2004; Chen, 2003). We included 19 statements to capture four dimensions of sustainable agriculture: production efficiency, economic viability, environmental sustainability and social responsibility. The second part measured extension workers' knowledge of select SAP, including 7 items developed in extant research. The final part was adopted from a study conducted by (Muma et al., 2010) which included 18 items. An expert translated the questionnaire into Bahasa Malaysian.

Before the survey was administered, a panel of experts checked the instrument for content and face validities. Reliability was estimated by calculating Cronbach's alpha coefficients and the instrument was 
found reliable. Respondents rated items using a semantic differential scale from 1 (strongly disagree) to 10 (strongly agree) for the first part of the questionnaire and from 1 (very low) to 10 (very high) for the second and third parts. There were several reasons for use of this scale. In an empirical review of several scale types, Allen and Rao (2000) reports a 10-point scale is preferred over a 5-point or 7-point Likert scale. The wider distribution of scores about the mean offers greater discriminating power. It is easier to establish covariance among or between variables with greater dispersion about their means. Ten-point scale measurement is accepted well in both academic and industrial research. Pallant (2010) contends that the 10-point scale offers respondents a wider range of scores and increases analysis available to respondents. An interpretive scale was developed: a mean of 1.00 to $3.99=$ Low (L), 4.00 to $6.99=$ moderate $(\mathrm{M})$ and 7.00 to $10.00=\operatorname{High}(\mathrm{H})$. Descriptive statistics-including means and standard deviations-were used to achieve study objectives.

\section{RESULTS}

Respondents provided demographic information including gender, age, ethnicity, level of education and tenure in extension services. Table 1 shows frequencies and percentages for demographic variables. The majority of extension workers were male (59.2, male; $40.8 \%$, female). Continuous variables were categorized. Noted in Table 1, the majority of respondents held a Certificate of Agriculture (73.3), 13.5 held a Diploma, 7.5\% held an SPM (Malaysian certificate of education) and $5.8 \%$ held a Bachelor's degree. Most respondents were 25 to 34 years $(35.3 \%)$ old in comparison to the 45 to 54 (29.8), 35 to 44 (14.8), under 25 (14.8) and over 55 (5.5\%) age groups. Ethnicity included $99.8 \%$ Malays and $0.3 \%$ Indians. Data showed that $47.5 \%$ of the extension workers had fewer than 5 years working experience with extension services, $34.3 \%$ had more than 12 years, $15.8 \%$ had between 5 and 10 years and $2.5 \%$ had between 11 and 16 years.

Table 2 presents means and standard deviations of extension workers' perceptions of SAP. Extension workers had a mean composite score of 8.30 on perceptions regarding select SA practices. Based on the 10-point scale, the minimum rating was 4.33 and the maximum was 10.00 , a range of 5.67. The median perception rating value was 8.40 with a standard deviation of 0.93. An interpretive scale was developed: a mean of 1.00 to $3.99=$ low/disagree, 4.00 to $6.99=$ moderate/agree and 7.00 to $10.00=$ high/highly agree. The overall mean perception rating was 8.30 , implying perceptions were high. The highest rated practice was integrated pest management $(\mathrm{M}=$ 9.01; $\mathrm{SD}=1.44)$. Results show that extension workers' perceptions of SAP are high/highly agree. In accord with ratings of low, moderate and high, $92.5 \%$ of extension workers rated highly when indicating perceptions of SAP, $7.5 \%$ rated moderate and none rated low (Table 3 ).

Table 1. Demographic profiles respondents $(n=400)$

\begin{tabular}{llrl}
\hline Variable & Category & Frequency & (\%) \\
\hline Gender & Male & 237 & 59.2 \\
Age group & Female & 163 & 40.8 \\
Under 25 & & 59 & 14.8 \\
25 to 34 & & 141 & 35.3 \\
35 to 44 & 59 & 14.8 \\
45 to 54 & 119 & 29.8 \\
Over 55 & & 22 & 5.5 \\
Ethnic & Malay & 399 & 99.8 \\
& Indian & 1 & 0.2 \\
Levels of education & SPM & 30 & 7.5 \\
& Certificate of 293 & 73.3 \\
& agriculture & \\
& Diploma & 54 & 13.5 \\
& Bachelor's & 23 & 5.8 \\
& degree & & \\
Tenure in extension services & Fewer than & 190 & 47.5 \\
& 5 years & \\
& 5 to 10 years & 63 & 15.8 \\
& 11 to 16 years 10 & 2.5 \\
& More than & 137 & 34.3 \\
& 16 years & \\
\hline
\end{tabular}

Table 2. Means and standard deviations of extension workers' perceptions of SAP

\begin{tabular}{lll}
\hline SA Practice & Mean & SD \\
\hline Integrated pest management & 9.01 & 1.44 \\
Soil testing & 8.91 & 1.11 \\
Crop rotation & 8.89 & 1.17 \\
Conservation tillage & 8.89 & 1.10 \\
Use of animal manure & 8.88 & 1.12 \\
Recycling agricultural wastes & 8.86 & 1.21 \\
Use of green manure & 8.84 & 1.36 \\
Reduced rates of herbicides & 8.60 & 1.63 \\
Insect resistant crop & 8.21 & 1.65 \\
Rotational grazing & 8.10 & 1.89 \\
Reduced tillage & 7.96 & 1.85 \\
Herbicide resistant crops & 7.54 & 1.92 \\
Reduced use of fertilizers & 7.33 & 2.15 \\
Reduced nitrogen fertilizer rates & 7.27 & 1.99 \\
Use of low input livestock facilities & 7.16 & 2.04 \\
\hline
\end{tabular}

Mean = 8.30; Minimum = 4.33; Maximum $=10.00 ;$ Range $=5.67$; edian $=8.40$ Note: $1=$ strongly disagree; $10=$ strongly agree 
Table 3. Frequencies and percentages of extension workers' perceptions of SAP

\begin{tabular}{lcr}
\hline Level & Frequency & \multicolumn{1}{c}{$\%$} \\
\hline Moderate & 30 & 7.50 \\
High & 370 & 92.50 \\
Total & 400 & 100.00 \\
\hline
\end{tabular}

Table 4. Means and standard deviations of extension workers' perceived knowledge of

\begin{tabular}{lll}
\hline Knowledge of SAP & Mean & SD \\
\hline IPM (pesticides management) & 8.46 & 1.66 \\
Crop diversification & 8.46 & 1.38 \\
Mulching (keeping soil covered) & 8.43 & 1.48 \\
Green manures & 8.39 & 1.53 \\
Crop rotation & 8.33 & 1.68 \\
Cover crops & 7.74 & 1.96 \\
Conservation tillage & 7.55 & 1.84 \\
\hline
\end{tabular}

Table 5. Frequencies and percentages of extension workers' perceived knowledge of select SAP

\begin{tabular}{lcr}
\hline Level & Frequency & \multicolumn{1}{c}{$\%$} \\
\hline Low & 2 & 0.50 \\
Moderate & 60 & 15.00 \\
High & 338 & 84.50 \\
Total & 400 & 100.00 \\
\hline
\end{tabular}

Table 6. Means and standard deviations of the extent to which extension workers communicate select SAP to farmers

\begin{tabular}{lll}
\hline SA Topic & Mean & SD \\
\hline Food safety & 8.78 & 1.47 \\
Crop rotation & 8.70 & 1.28 \\
Mulch weeding & 8.50 & 1.51 \\
Use of animal manure & 8.49 & 1.37 \\
IPM (pesticides management) & 8.47 & 1.43 \\
Covering crops & 8.38 & 1.49 \\
Use of green manure & 8.37 & 1.46 \\
Recycling agricultural wastes & 8.31 & 1.62 \\
Soil testing & 8.27 & 1.62 \\
Water quality & 8.23 & 1.69 \\
Reduce rates of herbicides & 8.20 & 1.74 \\
Nitrogen application & 7.78 & 1.73 \\
Renewal sources of energy & 7.49 & 1.96 \\
Reduced nitrogen fertilizer rates & 7.44 & 1.88 \\
Air pollution & 7.43 & 2.10 \\
Herbicide-resistant crops & 7.39 & 2.02 \\
Reduced tillage & 7.14 & 2.06 \\
Narrow strip intercropping & 7.06 & 2.06 \\
\hline
\end{tabular}

Table 7. Frequencies and percentages of the extent to which extension workers communicate select SAP to farmers

\begin{tabular}{lcr}
\hline Level & Frequency & $\%$ \\
\hline Low & 2 & 0.5 \\
Moderate & 62 & 15.5 \\
High & 336 & 84.5 \\
Total & 400 & 100.0 \\
\hline
\end{tabular}

Table 4 presents extension workers' perceived knowledge regarding select SAP. Respondents had a mean composite score of 8.19 on knowledge regarding select SAP. Based on the 10-point scale, the minimum rating was 3.00 and the maximum was 10.00 , a range of 5.67. The median rating was 8.28 with a standard deviation of 1.23. The overall means of the respondents on perceived knowledge of select SAP were divided into: 1.00 to $3.99=$ low, 4.00 to $6.99=$ moderate, 7.00 to $10.00=$ high. Based on this scale, extension workers rated their knowledge of select SAP highly. The toprated knowledge on select practices were IPMpesticides management $(\mathrm{m}=8.46 ; \mathrm{sd}=1.66)$ and crop diversification $(\mathrm{m}=8.46 ; \mathrm{sd}=1.38) .84 .5 \%$ of extension workers reported high knowledge of SAP, $15.0 \%$ reported moderate knowledge and $0.5 \%$ reported low knowledge (Table 5).

Table 6 present means and standard deviations of the extent extension workers communicate information on SAP to farmers. Based on the 10-point scale, the minimum rating was 3.00 and the maximum was 10.00 , a range of 7.00. The median rating value was 8.11 with a standard deviation of 1.05 . The mean rating of 8.02 implies the level information transfer is high. The overall means were categorized: 1.00 to $3.99=$ low, 4.00 to 6.99 $=$ moderate, 7.00 to $10.00=$ high. The extension workers reported they communicate information to farmers to high extent. Food safety reported as the highest rated category. $84.0 \%$ rated high communication with farmers, $15.5 \%$ rated moderate and $0.5 \%$ rated low (Table 7 ).

\section{DISCUSSION}

Findings of this study were similar to findings in existing studies (Coffnner and Kolodinsky, 1997; Udoto and Flowers, 2001; Connors et al., 2004; Chizari et al., 1999). Particularly, findings that extension workers perceive themselves as knowledgeable are similar to several studies (Coffnner and Kolodinsky, 1997; Bonne et al., 2007). Although sustainable agriculture is new in Malaysia, extension workers in west Malaysia indicated they possess positive perceptions on SAP. All extension workers were familiar with select SAP and were willing to transfer the information to farmers. Further research is needed to determine if this finding holds true for other extension workers at the DOA in west Malaysia and more research needs to be conducted in other Malaysian agricultural agencies to investigate extension workers' knowledge of SAP and the extent to which they communicate that knowledge to farmers. To acquire a better picture, it is recommended that further data collection to be undertaken. This study investigates 
only extension workers, so studies that examine SAPrelated extension work from the perspective of farmers who adopted SAP would expand understanding of extension workers' efforts.

Research needs to be conducted both from farmers' perspective of extension services and concerning the role of extension workers, specifically as an aspect of SAP adoption. To what extent does extension play a role in SAP adoption? Additionally, it is recommended to survey farmers who have not yet adopted SAP to examine program adoption barriers. What kinds of support, incentives and information do farmers need to adopt a program in future? Future investigations should determine farmers' perceptions of extension workers regarding what promotes SAP adoption in Malaysia. Replication of this study with other extension workers in other extension organizations/agencies is necessary to evaluate the extent to which results are similar. Studies incorporating qualitative approaches such as in-depth interviews with farmers concerning extension workers' knowledge and their efforts to deliver information to farmers would illuminate extension efficacy.

\section{CONCLUSION}

This study suggests Malaysia extension workers agree with SAP. In fact, they support the concept highly. Extension workers perceive themselves knowledgeable regarding selected SAP and they communicate information to farmers.

\section{ACKNOWLEDGMENT}

The reachers wish to thanks university Putra Malaysia to grant this study.

\section{REFERENCES}

Agunga, R.A., 1995. What Ohio extention agents say about sustainable agriculture? J. Sust. Agric., 5: 169187. DOI: $10.1300 / J 064 v 05 n 03 \_13$

Ahmad, F., 2001. Sustainable agriculture system in Malaysia. Proceedings of the Regional Workshop on Integrated Plant Nutrition System, Development in Rural Poverty Alleviation, Sept. 18-20, United Nations Bangkok, Thailand, pp: 1-10.

Allahyari, M.S., 2008. Extensionists' attitude toward sustainable agriculture in Iran. J. Applied Sci., 8: 3761-3763.
Allen, D.R. and T.R.N. Rao, 2000. Analysis of Customer Satisfaction Data: A Comprehensive Guide to Multivariate Statistical Analysis in Customer Satisfaction, Loyalty and Service Quality Research. 1st Edn., Asq Press, Milwaukee, ISBN-10: 0873894537, pp: 243.

Alonge, A.J. and R.A. Martin, 1995. Assessment of the adoption of sustainable agriculture practices: Implications. J. Agric. Educ., 3: 34-42. DOI: 10.5032/jae.1995.03034

Al-Subaiee, S.S.F., E.P. Yoder and J.S. Thomson, 2005. Extension agents' perceptions of sustainable agriculture in the riyadh region of Saudi Arabia. J. Int. Agric. Extension Educ., 12: 5-14. DOI: 10.5191/jiaee.2005.12101

Bell, M.M., M.S. Carolan, D. Mayerfeld and R. Exner, 2001. Professional development for the adoption of sustainable agriculture on rented land. Iowa State University, Ames, Iowa.

Bonne, H.N., E.M. Hersman, D.A. Boone and S.A. Gartin, 2007. Knowledge of sustainable agriculture practices by extension agents in Ohio, Pennsylvania, and West Virginia. J. Extension.

Chen, H.Y., 2003. Assessing Faculty Perceptions of the Ecological Paradigm of the College of Food, Agricultural and Environmental Sciences. 1st Edn., Ohio State University, pp: 210.

Chikwendu, D.O. and J.O. Arokoyo, 1997. Women and sustainable agricultural development in Nigeria. J. Sustain. Agric., 11:, 53-69. DOI: 10.1300/J064v11n01_06

Chizari, M., A.H.A. Baygi and D. Breazeale, 2006. Analysis of the training needs of multi-functional extension agents associated with sustainability. J. Int. Agric. Extension Educ., 13: 51-58. DOI: 10.5191 jiaee.2006.13105

Chizari, M., J.R. Lindner and M. Zoghie, 1999. Perceptions of extension agents' educational needs regarding sustainable agriculture in the khorasan province, Iran. J. Agric. Educ., 40: 20-27. DOI: 10.5032/jae.1999.04020

Coffnner, D. and J. Kolodinsky, 1997. Can you teach an old dog new tricks? An evaluation of extension training in sustainable agriculture. J. Sustain. Agric. 10: 5-20. DOI: 10.1300/J064v10n04_03

Connors, J.J., B. Swan and J.A. Brousseau, 2004. Perceptions of Lithuanian agriculture teachers towards the ecological paradigm. Proceedings of the 20th Annual Conference, (AC' 04), Dublin, Ireland, pp: 506-518. 
Fairweather, J.R. and H.R. Campbell, 2003. Environmental beliefs and farm practices of New Zealand farmers contrasting pathways to sustainability. Agric. Hum. Values, 20: 287-300. DOI: $10.1023 / \mathrm{A}: 1026148613240$

Minarovic, R.E. and J.P. Mueller, 2000. North carolina cooperative extension service professionals' attitudes toward sustainable agriculture. J. Extension.

Muma, M., R. Martin, M. Shelley and J.L. Holmes, 2010. Sustainable agriculture: Teacher beliefs and topics taught. J. Sustain. Agric., 34: 439-459. DOI: 10.1080/10440041003680312

Murad, M.W., N.H. Musatfa and C. Siwar, 2008. Review of malaysian agricultural policies with regards to sustainability. Am. J. Environ. Sci., 4: 608-614. DOI: 10.3844/ajessp.2008.608.614

Pallant, J., 2010. SPSS Survival Manual: A Step by Step Guide to Data Analysis Using SPSS. 4th Edn., McGraw-Hill International, ISBN-10: 0335242391, Maidenhead, pp: 352.

Salleh, M., H. Yunus and N. Osman, 2007. Status and perspectives on good agricultural practices in Malaysia. Malaysian Agricultural Research and Development Institute (MARDI), Kala Lumpur, Malaysia.
Singh, S.P. and S. Osawaru, 1990. Lowinput/sustainable agriculture: Implications for small farms. Proceedings of the 16th Annual Convention of the Eastern Economic Association, Mar. 30-Apr. 1, Cincinnati, Ohio.

Tiraieyari, N. and J. Uli, 2011. Sustainable agriculture in Malaysia: Implication for extension workers. J. Am. Sci., 7: 179-182.

Udoto, M. and J. Flowers, 2001. Perceptions of agricultural education teachers toward sustainable agricultural practices. Proceedings of the 28th Annual National Agricultural Education Research Conference, Dec. 12-12, Egerton University, Kenya, pp: 433-444.

Williams, D.L., 2000. Students' knowledge of and expected impact from sustainable agriculture. J. Agric. Educ. 41: 19-24.

Barrow, C.J., C.N. Weng and T. Masron, 2009. Issues and challenges of sustainable agriculture in the cameron highlands. Malaysian J. Environ. Manage., 10: 89-114.

Straquadine, G.S., 1985. Marital Satisfaction as Perceived by the Spouses of the Vocational Agriculture Teachers in New Mexico. M.A. Thesis, New Mexico State University. 